Tropical Journal of Pharmaceutical Research March 2016; 15 (3): 657-662

ISSN: $1596-5996$ (print); 1596-9827 (electronic)

(C) Pharmacotherapy Group, Faculty of Pharmacy, University of Benin, Benin City, 300001 Nigeria.

All rights reserved.

Available online at http://www.tjpr.org

Original Research Article

http://dx.doi.org/10.4314/tjpr.v15i3.31

\title{
Autoimmune Response Confers Decreased Cardiac Function in Patients with Rheumatic Mitral Lesion following Valve Replacement
}

\author{
Zheng-Chun Zhou, Qiong Zhang, Zhi-Wei Zhao and Jian-Jun Ge* \\ Department of Cardiovascular Surgery, The First Affiliated Hospital of Anhui Medical University, Hefei 230032, China
}

*For correspondence: Email: anyidage@126.com; Tel: +86-551-62922042; Fax: +86-551-63633742

Received: 4 February 2015

Revised accepted: 11 December 2015

\begin{abstract}
Purpose: To explore the effect of autoimmune response on the decreased cardiac function in patients with rheumatic mitral lesion following valve replacement.

Methods: In this case-controlled study, 29 patients who had undergone valve replacement as a result of mitral lesion were enrolled (mean age $=48.7$ years). Twenty healthy volunteers were selected as control (mean age $=47.5$ years). Plasma levels of tumor necrosis factor- $\alpha$ (TNF- $\alpha$ ), interleukin-6 (IL-6), high -sensitivity C-reactive protein (hs-CRP) and echocardiographic indices of heart function in the two groups were investigated, respectively. Body mass index (BMI) was also calculated.

Results: TNF- $\alpha$, IL-6 and hs-CRP levels in plasma were significantly higher than those in controls $(p<$ $0.05 ; 22.23 \mathrm{pg} / \mathrm{mL}$ vs. $13.24 \mathrm{pg} / \mathrm{mL}, 53.42 \mathrm{pg} / \mathrm{mL}$ vs. $9.57 \mathrm{pg} / \mathrm{mL}$, and $2.12 \mu \mathrm{g} / \mathrm{mL}$ vs. $0.97 \mu \mathrm{g} / \mathrm{mL}$, respectively). The indices of left atrial diameter ( $L A D)$, left ventricular end-diastolic diameter (LDD) and isovolumetric contraction time (ICT) were significantly higher ( $p<0.05 ; 4.72 \mathrm{~cm}$ vs. $3.78 \mathrm{~cm}, 4.85 \mathrm{~cm}$ vs. $4.37 \mathrm{~cm}$, and $76.38 \mathrm{~ms} v \mathrm{vs} .66 .24 \mathrm{~ms}$, respectively), but those of early diastolic velocity (Ea), late diastolic velocities (Aa) and ejection time (ET) were significantly lower $(p<0.05 ; 7.65 \mathrm{~cm} / \mathrm{s} v \mathrm{vs} .16 .8$ $\mathrm{cm} / \mathrm{s}, 5.56 \mathrm{~cm} / \mathrm{s}$ vs. $12.9 \mathrm{~cm} / \mathrm{s}$, and $261.54 \mathrm{~ms}$ vs. $276.14 \mathrm{~ms}$, respectively). Two-dimensional echocardiography obtained the same results.

Conclusion: Valve replacement in patients with rheumatic heart disease (RHD) does not attenuate inflammatory response; rather, autoimmune response would keep affecting decreased heart function in RHD patients who have received mitral valve replacement.
\end{abstract}

Keywords: Tumor necrosis factor-a, Interleukin-6, High sensitivity C-reactive protein, Mitral lesion, Mitral valve replacement

Tropical Journal of Pharmaceutical Research is indexed by Science Citation Index (SciSearch), Scopus, International Pharmaceutical Abstract, Chemical Abstracts, Embase, Index Copernicus, EBSCO, African Index Medicus, JournalSeek, Journal Citation Reports/Science Edition, Directory of Open Access Journals (DOAJ), African Journal Online, Bioline International, Open-J-Gate and Pharmacy Abstracts

\section{INTRODUCTION}

Rheumatic fever (RF) is a delayed consequence of throat infection by Streptococcus pyogenes, and often affects susceptible untreated children. Nearly $30-45 \%$ of the affected children could develop progressive and permanent valvular lesions, and leading to rheumatic heart disease (RHD). There are 15.6 million new cases of RHD per year worldwide, resulting in 233,000 deaths per year in developing countries [1]. The epidemiological data demonstrated that RHD is a crucial health problem.

Currently, the mechanism of RHD is still far from being understood. The pathogenesis of RHD is complex, and potential reasons include cellular responses of Streptococcus pyogenes and autoimmune humoral responses toward human tissues [2]. The mechanism of molecular mimicry 
is the process whereby $T$ cells recognize selfantigens, mainly the $M$ protein of heart tissue, which shares homology with streptococcal antigens. Once activated, the T cells from RHD patients were able to recognize streptococcal $M$ protein peptides as well as myocardium and valvular proteins, resulting in valvular lesions [3]. According to this pre-supposition, the process of autoimmune response should be eradicated after valve replacement by removing the valvular proteins and the heart function of RHD patients should be recovered. However, increasing clinical evidences indicated that the painful symptom still existed in most RHD patients after valve replacement. Therefore, mechanism of this phenomenon still remains uncertain.

It has been noted that the autoimmune response status can be reflected by evaluating the cytokines' levels [4]. A large number of studies have demonstrated that the production of inflammatory cytokines, including tumor necrosis factor (TNF)- $\alpha$, interleukin (IL)-6 and highsensitivity C-reactive protein (hs-CRP), were increased after streptococcal antigen and pokeweed mitogen stimulation [5]. Therefore, the elevated levels of TNF- $\alpha$, IL-6 and hs-CRP appear to play critical roles in triggering immunological and inflammatory reactions of RHD patients. In this study, it was hypothesized that the autoimmune response would persistently exist in RHD patients who have received heart valve replacement.

Clinically, two-dimensional echocardiography is widely used as an effective approach to evaluate cardiac function heart function of patients with RHD [6], thus the echocardiographic indices were measured to evaluate the heart function, and the plasma levels of TNF- $\alpha$, IL- 6 and hsCRP were detected to investigate whether the autoimmune response affect the RHD patients receiving valve replacement or not. Also, the relationship between the plasma levels of TNF- $\alpha$, IL-6, CRP and echocardiographic indices were analyzed to further explore the pathogenesis mechanism of the RHD patients who have received heart valve replacement.

\section{EXPERIMENTAL}

\section{Subjects and study protocol}

One thousand and five patients had undergone mitral valve replacement during January 2008 to May 2010 at the First Affiliated Hospital of Anhui Medical University. Of which, twenty-nine patients (mean age $=48.7 \pm 7.2$ years) were selected in this study. Rheumatic mitral lesions in the patients prior to operation were evaluated based on the clinical classification of New York Heart Association (NYHA). Six of the 29 selected patients were classified as NYHA class II, fifteen as class III, and eight as class IV. The operations were performed by the identical surgeons in the hospital.

The instrumental prosthetic valves implanted were provided by Sorin Group (Italian). Heart function of the patients was recovered to NYHA class I after valve replacement. Additional 20 healthy volunteers were recruited as the controls and were matched by age and gender (mean age $=47.5 \pm 6.8$ years). Subjects from either group were excluded if they had a history of cerebrovascular events, hyperlipidemia, venous thrombosis, diabetes, pulmonary diseases, disease of immune system, degenerative neurologic disorders, renal or liver disease, acute rheumatic fever, acute infection, inflammatory disease, malignancy, acute myocardial infarction, recent major surgery, trauma, and other chronic cardiovascular diseases such as hypertension and coronary heart disease.

Informed consents were obtained from all study patients. Weight was measured to the nearest $0.1 \mathrm{~kg}$ and calibrated with known weights and height was measured to the nearest $0.1 \mathrm{~cm}$ by using a stadiometer at the enrollment into the department of Cardiovascular Surgery in the First Affiliated Hospital of Anhui Medical University. Body mass index (BMl; $\mathrm{kg} / \mathrm{m}^{2}$ ) was calculated.

The patients continued treatment with digoxigenin, anticoagulant and diuretic for three months after the operation. The time course from the valve replacement surgery to the enrolment in this study was 3-29 months, and the average time was 15.3 months. The study protocol was approved by the Institutional Ethic Committee, Anhui Medical University (no. AHM-2007105\#).

\section{Measurement of TNF- $\alpha$ and IL- 6}

Blood samples of the patients were collected into an evacuated tube containing $3.8 \%$ buffered sodium citrate. Plasma fractions were obtained by centrifugation for $10 \mathrm{~min}$ at $2000 \mathrm{rpm}$ at room temperature, and aliquots were prepared and stored at $-80^{\circ} \mathrm{C}$ until the assay. Plasma levels of TNF- $\alpha$ and IL- 6 were measured according to the manufacturer protocols of $A B C$-ELISA (R\&D).

\section{Measurement of hs-CRP}

Hs-CRP was measured by latex-enhanced immunoturbidimetric assay with automatic 
biochemistry analyzer (ADVIA Chemistry System, Bayer HealthCare AG, Leverkusen, Modular-P Switzerland). Both antiserum and standard substance were supplied by the DiaSys Diagnostic Systems Co., Ltd (Shanghai).

\section{Echocardiographic examination}

Both the patients and healthy volunteers underwent transthoracic two-dimensional and Tissue Doppler Echocardiographic examination by means of the Philips iE33 system with a 5.0 $\mathrm{MHz}$ transducer. All echocardiographic examinations were assessed by an identical skilled cardiologist. Transthoracic echocardiographic measurements were obtained from the parasternal long-axis view by twodimensional targeted M-mode tracing.

Left ventricular end-diastolic diameter (LDD) and left ventricular ejection fraction (LVEF) were measured to assess the left ventricles function, and left atrial diameter (LAD) was measured to reflect the function of the left atrium. LVEF and LDD were used as the most convenient and sensitive indices to estimate the left ventricular function [7]. Besides, LAD was used to assess the left atrium function [8].

Using the 4-chamber view, a 2-mm sample volume was placed at the lateral corner of the tricuspid valve annulus and early diastolic (Ea) and late diastolic $\mathrm{(Aa}$ ) myocardial velocities were obtained to evaluate the right heart function. Meanwhile, the indices of $E / A$, isovolumetric contraction time (ICT), isovolumetric relaxation time (IRT) and Tei index were measured to assess the right heart function. In addition, ECG tracings were performed.

The indices of Ea, Aa, E/A, ET, ICT and IRT were demonstrated to be effective to assess the function of right heart $[9,10]$. The Tei index was defined based on the formula: Tei $=($ ICT + IRT)/ET, to appraise a combined systolic and diastolic right cardiac function [11].

\section{Statistical analysis}

The results were expressed as mean \pm standard error of the mean (SEM). Analysis of the plasma levels of TNF- $\alpha$, IL- 6 and hs-CRP and the indices of heart function between the cases and the controls were performed using Independentsamples $T$ test.

$P<0.05$ was considered statistically significant. All analyses were conducted by using statistical software SPSS 13.0.

\section{RESULTS}

\section{Plasma levels of TNF- $\alpha$, IL- 6 and hs -CRP in the groups}

The plasma concentrations of TNF- $\alpha$, IL- 6 and hs-CRP in each group were summarized in Table 1. The levels of TNF- $\alpha$, IL- 6 and hs -CRP levels were found to be significantly higher in the cases than in the controls $(p<0.01 ; 22.23 \mathrm{pg} / \mathrm{L}$ vs. $13.24 \mathrm{pg} / \mathrm{L}, 53.42 \mathrm{pg} / \mathrm{L}$ vs. $9.57 \mathrm{pg} / \mathrm{L}$, and 2.12 $\mu \mathrm{g} / \mathrm{mL}$ vs. $0.97 \mu \mathrm{g} / \mathrm{mL}$, respectively).

Table 1: Characteristics of participants

\begin{tabular}{|c|c|c|c|}
\hline Variable & Case $(n=29)$ & Control $(n=20)$ & $P$-value \\
\hline Age (years) & $48.7 \pm 7.2$ & $47.5 \pm 6.8$ & 0.5604 \\
\hline Female (\%) & 62.1 & 65 & 0.8343 \\
\hline Height $(\mathrm{cm})$ & $167.1 \pm 7.8$ & $168.2 \pm 8.1$ & 0.6351 \\
\hline Weight (kg) & $61.8 \pm 11.2$ & $67.3 \pm 11.7$ & 0.0954 \\
\hline BMI (kg/m2) & $21.7 \pm 4.1$ & $23.1 \pm 4.3$ & 0.2552 \\
\hline$T N F-\alpha(p g / m L)$ & $22.23 \pm 10.56$ & $13.24 \pm 8.76$ & 0.003 \\
\hline IL-6 (pg/mL) & $53.42 \pm 20.13$ & $9.57 \pm 8.14$ & $<0.001$ \\
\hline Hs-CRP $(\mu g / m L)$ & $2.12 \pm 1.98$ & $0.97 \pm 0.57$ & $<0.001$ \\
\hline $\mathrm{Ea}(\mathrm{cm} / \mathrm{s})$ & $7.65 \pm 1.78$ & $16.8 \pm 1.57$ & $<0.0001$ \\
\hline $\mathrm{Aa}(\mathrm{cm} / \mathrm{s})$ & $5.56 \pm 2.00$ & $12.9 \pm 1.97$ & $<0.0001$ \\
\hline$E / A$ & $1.49 \pm 0.47$ & $1.62 \pm 0.41$ & $>0.05$ \\
\hline $\operatorname{ICT}(\mathrm{ms})$ & $76.38 \pm 15.04$ & $66.24 \pm 13.45$ & 0.0195 \\
\hline $\operatorname{IRT}(\mathrm{ms})$ & $80.21 \pm 16.21$ & $75.13 \pm 12.04$ & $>0.05$ \\
\hline$E T(m s)$ & $261.54 \pm 4.66$ & $276.14 \pm 19.72$ & 0.0046 \\
\hline$L A D(\mathrm{~cm})$ & $4.72 \pm 1.08$ & $3.78 \pm 0.89$ & 0.0024 \\
\hline$L D D(\mathrm{~cm})$ & $4.85 \pm 0.54$ & $4.37 \pm 0.58$ & 0.0047 \\
\hline$E F(\%)$ & $59.72 \pm 6.08$ & $67.27 \pm 6.25$ & 0.0001 \\
\hline
\end{tabular}

Data are expressed as mean \pm SEM 

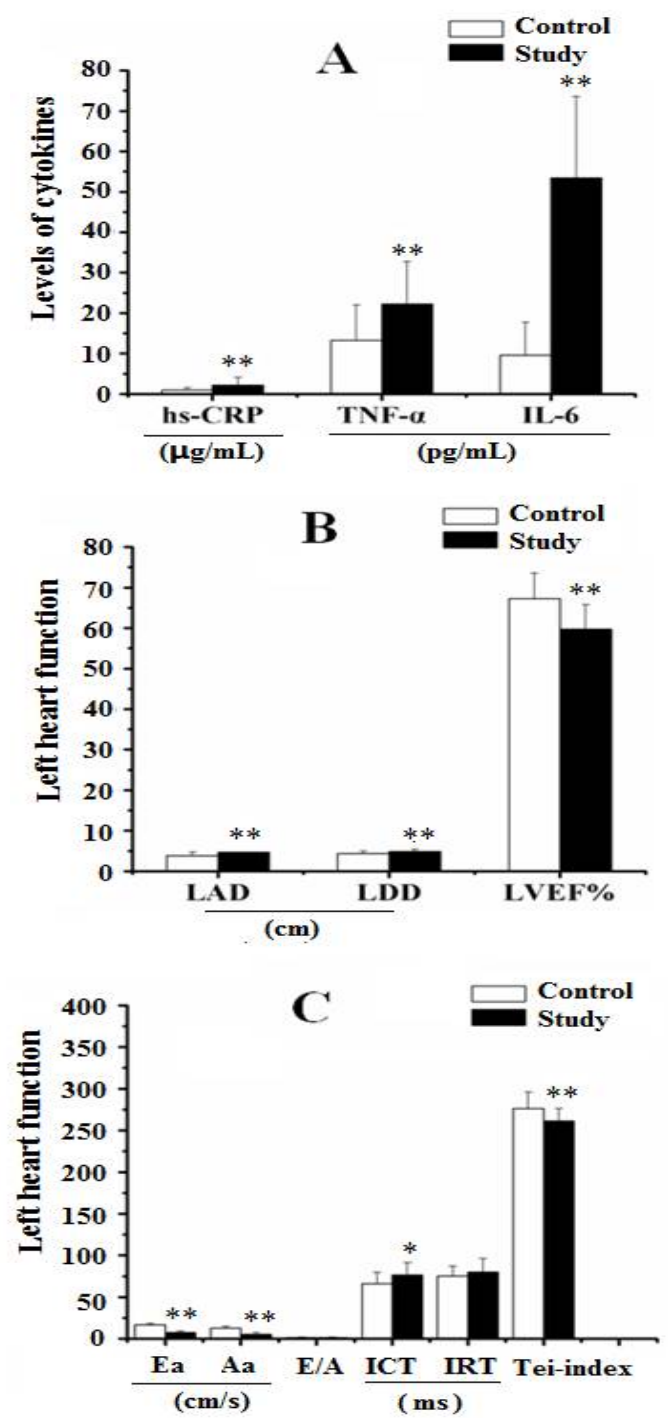

Figure 1: Figure 1A shows the levels of TNF-a, IL-6 and hs-CRP and heart function in the cases and the controls; Figure $1 \mathrm{~B}$ revealed the changes of echocardiography parameters of left heart function between the cases and the controls. In this study, the values of LAD and LDD were higher in the cases $(p=$ 0.0024 and 0.0047 , respectively), but the value of LVEF was lower $(p<0.0001)$; Figure $1 \mathrm{C}$ demonstrates the changes of echocardiography indices of right heart function between the two groups. Compared to the controls, lower Ea, Aa and ET and higher ICT values were found in the cases $(p<0.0001, p<0.0001$, $p=0.0046$ and $p=0.0195$, respectively). No statistical difference was found in the indices of IRT, and Teiindex between the two groups

Comparison of two-dimensional echocardiography indices between the cases and control

The echocardiography parameters of the left and right heart function in the two groups were shown in Figure 1A. Compared with the control group, the indices of LAD and LDD were higher in the cases $(p<0.01,4.72 \mathrm{~cm}$ vs. $3.78 \mathrm{~cm}$ and 4.85 $\mathrm{cm}$ vs. $4.37 \mathrm{~cm}$ respectively), but the value of LVEF (\%) was lower $(p<0.0001$, Figure 1B). The indices of Ea, Aa and ET in the cases were significantly lower than those in the controls $(p<$ $0.05 ; 7.65 \mathrm{~cm} / \mathrm{s}$ vs. $16.8 \mathrm{~cm} / \mathrm{s}, 5.56 \mathrm{~cm} / \mathrm{s}$ vs. 12.9 $\mathrm{cm} / \mathrm{s}$, and $261.54 \mathrm{~ms}$ vs. $276.14 \mathrm{~ms}$, respectively; $p<0.001, p<0.001$ and $p<0.01$, respectively), but the index of ICT was higher ( $p$ $=0.0195$, Figure 1C). The values for IRT and Tei index in the cases and the controls were similar to each other.

\section{DISCUSSION}

In this study, it was found that the levels of TNF$\alpha$, IL- 6 and hs-CRP in plasma of the cases that received valve replacement were significantly higher than those in the controls. LAD and LDD represented the function of the left atrium, and LVEF indicated the function of the left ventricle. Echocardiography examination results indicated that the heart function was obviously poorer in the cases compared with the controls. The results also indicated that inflammatory process kept affecting the patients received valve replacement. Damaged valves would not be the exclusive source that induced immune reaction in the RHD patients.

Rheumatic fever is autoimmune in nature and results from the production of auto-reactive antibodies and T-cells cross-reactive to the components of group A streptococcus and host tissues. It is evident that $\mathrm{T}$ lymphocytes are involved in the pathogenesis of rheumatic carditis, and the previous data supported the hypothesis that antibodies play important roles in the initiation of the disease at the valve endothelium [12]. The elevated levels of proinflammatory cytokine are the direct evidences of the presence of the autoimmune reaction. Previous investigations demonstrated that overproduction of TNF- $\alpha$ promoted the induction of post-infection autoimmune response in RHD [13]. The previous data discovered that both the production in the plasma and the expression of TNF- $\alpha$ in the myocardium were significantly higher in patients with rheumatic mitral lesion [14]. Increased serum level of IL-6 occurred in the patients with congestive heart failure [15] and in the patients with RHD [16]. Additional IL-6 might be secreted by the intralesional mononuclear cells from heart lesions predominantly in chronic RHD patients [17]. Moreover, increasing evidences showed CRP was a critical marker in assessing inflammation and tissue injury $[18,19]$. The plasma 
concentration of hs-CRP was significantly higher in $\operatorname{RHD}[20,21]$ and could reflect progression and outcome of the rheumatic mitral lesion [22]. In this study, it was found that concentrations of TNF- $\alpha$, IL- 6 and hs-CRP in plasma were obviously higher in cases group than those in controls, suggesting excising primary mitral lesions did not obviously enable attenuate the autoimmune response triggered by Streptococcus pyogenes in the cases group.

In previous investigations, there were few studies regarding immune reactions in postoperative patients. In this present study, we focused on whether immune reaction affects the outcome of valve replacement and improvement of cardiac function or not. We found that levels of TNF-a, IL-6 and hs-CRP in plasma were significantly higher in the case groups than those in healthy control groups. The over-production of cytokines could be secreted by $T$ cells in response to autoimmune reaction which caused by the infection of $\beta$-hemolytic group A streptococci. Thus, it is advisable to conversely deduce that high levels of the TNF-a, IL- 6 and hs-CRP could attribute to the active process of the autoimmune response in patients who undergone valve replacement. In the present research, it was demonstrated that immune reaction in RHD patients would occur even after valve replacement; another potential antigen that induced immune reaction in patients would be prosthetic valve. The mechanical prosthetic valve would act as an allotransplant to elicit the immune reaction [23]. Therefore, it was suggested that the valve replacement could not completely improve the cardiac function of RHD patients. Implementing anti-cytokines (such as anti-IL-6, anti-TNF- $\alpha$ and anti-hs-CRP) and administration of the inhibitor of p38MAPK could be the effective alternative modalities to prevent valve damage in RHD patients and to suppress the immune reaction in the patients received valve replacement.

\section{CONCLUSION}

The cardiac function of RHD patients did not fully recover after valve replacement due to synchronous influence of the autoimmune reaction. The elevated levels of plasma TNF- $\alpha$, IL-6 and hs-CRP appear to be indices of autoimmune activities. And it seems that the antiautoimmune therapy administered to group- $A$ streptococcus is an option for RHD patients after valve replacement.

\section{ACKNOWLEDGEMENT}

This study was supported by Science and Technology Department of Anhui Province (PR China) Grant (Key projects, grant no. 07020303071).

\section{REFERENCES}

1. Carapetis JR, Steer AC, Mulholland EK, Weber M. The global burden of group A streptococcal diseases. Lancet Infect. Dis 2005; 5(11): 685-694.

2. Guilherme L1, Ramasawmy R, Kalil J. Rheumatic fever and rheumatic heart disease: genetics and pathogenesis. Scand. J. Immunol 2007; 66(2-3): 199207.

3. Guilherme L, Cunha-Neto E, Coelho V, Snitcowsky $R$, Pomerantzeff PM, Assis $R V$, et al. Human heartinfiltrating $T$-cell clones from rheumatic heart disease patients recognize both streptococcal and cardiac proteins. Circulation 1995; 92(3): 415-420.

4. Ireland SJ, Monson NL, Davis LS. Seeking balance: Potentiation and inhibition of multiple sclerosis autoimmune responses by IL-6 and IL-10. Cytokine, 2015, 73(2):236-244.

5. Miller LC, Gray ED, Mansour M, Abdin ZH, Kamel R, Zaher S, Regelmann WE. Cytokines and immunoglobulin in rheumatic heart disease: production by blood and tonsillar mononuclear cells. J. Rheumatol. 1989, 16(11): 1436-1442.

6. Sekuri C, Utuk O, Bayturan O, Bilge A, Kurhan Z, Tavli T. Effect of losartan on exercise tolerance and echocardiographic parameters in patients with mitral regurgitation. J Renin Angiotensin Aldosterone Syst. 2008; 9(2): 107-111.

7. Rivas-Gotz $C$, Manolios $M$, Thohan $V$, Nagueh SF. Impact of left ventricular ejection fraction on estimation of left ventricular filling pressures using tissue Doppler and flow propagation velocity. Am J Cardiol 2003; 91(6): $780-784$.

8. Abhayaratna WP, Seward JB, Appleton CP, Douglas PS, Oh JK, Tajik AJ, et al. Left atrial size: physiologic determinants and clinical applications. J Am Coll Cardiol 2006; 47(12): 2357-2363.

9. Harada K, Toyono M, Yamamoto F. Assessment of right ventricular function during exercise with quantitative Doppler tissue imaging in children late after repair of tetralogy of Fallot. J Am Soc Echocardiogr 2004; 17(8): 863-869.

10. Schwarz ER, Dashti R. Right ventricular diastolic dysfunction in heart failure. Cardiovasc J Afr 2010; 21(4): 212-220.

11. Yasuoka K, Harada K, Toyono M, Tamura M, Yamamoto F. Tei index determined by tissue Doppler imaging in patients with pulmonary regurgitation after repair of tetralogy of Fallot. Pediatr Cardiol 2004; 25(2): 131-136.

12. Galvin JE, Hemric ME, Ward K, Cunningham MW. Cytotoxic $M A B$ from rheumatic carditis recognizes heart valves and laminin. J Clin Invest 2000; 106(2): 217-224. 
13. Settin A1, Abdel-Hady H, El-Baz R, Saber I. Gene Polymorphisms of TNF-a-308, IL-10-1082, IL-6-174, and IL-1RaVNTR Related to Susceptibility and Severity of Rheumatic Heart Disease. Pediatr Cardiol 2007; 28(5): 363-371.

14. Chang CJ, Hsu LA, Chiang CW, Ko YS, See LC, Shen YC, Ko YL, Kou CT, Lee YS, Pang JH. Percutaneous transvenous mitral valvulotomy normalizes elevated circulating levels of tumor necrosis factor-alpha and interleukin-6 in mitral stenosis with heart failure. Am J Cardiol 2003; 91(8): 1018-1020.

15. Pan JP, Liu TY, Chiang SC, Lin YK, Chou CY, Chan WL, Lai ST. The value of plasma levels of tumor necrosis factor-alpha and interleukin- 6 in predicting the severity and prognosis in patients with congestive heart failure. $J$ Chin Med Assoc 2004; 67(5): 222-228.

16. Guilherme L, Köhler KF, Kalil J. Rheumatic heart disease: mediation by complex immune events. Adv Clin Chem 2011; 53: 31-50.

17. Luiza Guilherme, Patricia Cury, Lea M.F. Demarchi, Vero'nica Coelho, Lu' cia Abel, Ana P. Lopez, et al. Rheumatic Heart Disease Proinflammatory Cytokines Play a Role in the Progression and Maintenance of Valvular Lesions. American Journal of Pathology 2004; 165(5): 1583-1591.

18. Jialal I, Devaraj S, Venugopal SK. C-Reactive protein: risk marker or mediator in atherothrombosis? Hypertension 2004; 44(1): 6-11.
19. Wang L, Liu ZQ, Huo YQ, Yao LJ, Wei XG, Wang YF. Change of hs-CRP, sVCAM-1, NT-proBNP levels in patients with pregnancy-induced hypertension after therapy with magnesium sulfate and nifudipine. Asian Pac J Trop Med 2013; 6(11): 897-901.

20. Chiu-Braga YY, Hayashi SY, Schafranski M, MessiasReason IJ. Further evidence of inflammation in chronic rheumatic valve disease (CRVD): high levels of advanced oxidation protein products (AOPP) and high sensitive $C$-reactive protein ( $h s-C R P)$. Int $J$ Cardiol 2006; 109(2): 275-276.

21. Davutoglu V, Celik A, Aksoy M. Contribution of selected serum inflammatory mediators to the progression of chronic rheumatic valve disease, subsequent valve calcification and NYHA functional class. J Heart Valve Dis 2005; 14(2): 251-256.

22. Zehra Gollbasia, Ozgul Ucar, Telat Kelesa, Ahmet Sahinb, Kerim C aglic, Ahmet $C$ amsaria, et al. Increased levels of high sensitive $C$-reactive protein in patients with chronic rheumatic valve disease: evidence of ongoing inflammation. Eur J Heart Fail 2002; 4(5): 593-595.

23. Frick C, Dietz AC, Merritt K, Umbreit TH, Tomazic-Jezic $V J$. Effects of prosthetic materials on the host immune response: evaluation of polymethyl-methacrylate (PMMA), polyethylene (PE), and polystyrene (PS) particles. J Long Term Eff Med Implants 2006; 16(6): 423-433. 